Опыт применения транскраниальной электростимуляции в оценке микроциркуляторного русла методом бесконтрастной магнитно-резонансной перфузии у пациентов с хронической ишемией головного мозга

\author{
Чухонцева Е.С., Морозова Т.Г., Борсуков А.В.
}

ФГБОУ ВО «Смоленский государственный медицинский университет» Минздрава России, ул. Крупской, 28, Смоленск, 214019, Российская Федерация

\begin{abstract}
Чухонцева Екатерина Сергеевна, науч. сотр. научного исследовательского центра ФГБОУ ВО «Смоленский государственный медицинский университет» Минздрава России;

http://orcid.org/0000-0003-4571-2354

Морозова Татьяна Геннадьевна, д. м. Н., заведующая кафедрой лучевой диагностики и лучевой терапии, ст. науч. сотр. проблемной научно-исследовательской лаборатории «Диагностические исследования и малоинвазивные технологии» ФГБОУ ВО «Смоленский государственный медицинский университет» Минздрава России;

http://orcid.org/0000-0003-4983-5300

Борсуков Алексей Васильевич, д. М. Н., профессор, директор проблемной научно-исследовательской лаборатории «Диагностические исследования и малоинвазивные технологии» ФГБОУ ВО «Смоленский государственный медицинский университет» Минздрава России;

http://orcid.org/0000-0003-4047-7252
\end{abstract}

\begin{abstract}
Резюме
Цель: определить роль транскраниальной электростимуляции в оценке микроциркуляторного русла методом бесконтрастной магнитно-резонансной (MP) перфузии у пациентов с хронической ишемией головного мозга.

Материал и методы. Обследованы 37 человек в возрасте 65-70 лет с диагнозом «хроническая ишемия головного мозга». Пациенты были ранжированы на две группы: с когнитивными расстройствами и без них. Алгоритм исследования включал: МР-томографию (МРТ) головного мозга (Toshiba Vantage Titan, 1.5 T), транскраниальную электростимуляцию (ТЭС) с помощью компьютеризированного аппаратно-диагностического комплекса ТЭТОС (НПФ «БИОСС»), повторную МРТ головного мозга в режиме ASL-перфузии (arterial spin labeling - артериальная спиновая маркировка). По данным результатам ASL-перфузии оценивали церебральный кровоток в зонах интереса до и после ТЭС.

Результаты. По данным бесконтрастной МР-перфузии выявлена относительная гиперперфузия в коре лобных и теменных долей в сочетании с гипоперфузией подкорковых ядер и белого вещества мозга у пациентов с когнитивными расстройствами, что свидетельствует о неэффективности усиления коркового кровотока и сформировавшемся шунтирующем кровотоке. Под влиянием ТЭС выявлено статистически значимое изменение церебральной перфузии в группе пациентов с хронической ишемией головного мозга без когнитивных расстройств. После воздействия ТЭС у больных без когнитивных расстройств методом ASL-перфузии отмечено диффузное усиление церебрального кровотока ( $p=0,002)$, тогда как в группе условно здоровых добровольцев подобного нарастания кровотока не выявлено.

Заключение. Показатели церебральной перфузии до и после ТЭС у пациентов всех исследуемых групп определяют роль ТЭС как дополняющего звена в оценке компенсаторных возможностей микрососудистого русла методом бесконтрастной МР-перфузии при хронической ишемии головного мозга.

Ключевые слова: транскраниальная электростимуляция; хроническая ишемия головного мозга; ASLперфузия; магнитно-резонансная томография; скорость церебрального кровотока.

Конфликт интересов. Авторы заявляют об отсутствии конфликта интересов.

\section{Участие авторов}

Чухонцева Е.С. - проведение исследования, сбор и статистическая обработка данных, анализ и интерпретация полученных данных, написание текста;

Морозова Т.Г. - концепция и дизайн исследования, анализ и интерпретация полученных данных, подготовка и редактирование текста, ответственность за целостность всех частей статьи;

Борсуков А.В. - концепция и дизайн исследования, утверждение окончательного варианта статьи
\end{abstract}


Для цитирования: Чухонцева Е.С., Морозова Т.Г., Борсуков А.В. Опыт применения транскраниальной электростимуляции в оценке микроциркуляторного русла методом бесконтрастной магнитно-резонансной перфузии у пациентов с хронической ишемией головного мозга. Вестник рентгенологии и радиологии. 2021; 102(6): 369-76. https://doi.org/10.20862/0042-4676-2021-102-6-369-376

Для корреспонденции: Чухонцева Екатерина Сергеевна, E-mail:chukhontsevaes@mail.ru

\title{
Experience with Transcranial Electrical Stimulation in the Assessment of the Microvascular Bed by Contrast-Free Magnetic Resonance Perfusion Imaging in Patients with Chronic Cerebral Ischemia
}

\section{Ekaterina S. Chukhontseva, Tatiana G. Morozova, Aleksey V. Borsukov}

Smolensk State Medical University, ul. Krupskoy, 28, Smolensk, 214019, Russian Federation

Ekaterina S. Chukhontseva, Researcher, Scientific Research Center, Smolensk State Medical University; http://orcid.org/0000-0003-4571-2354

Tatiana G. Morozova, Dr. Med. Sc., Chief of Chair of Radiation Diagnostics and Therapy, Chief Researcher, Problem Research Laboratory "Diagnostic Studies and Minimally Invasive Technologies", Smolensk State Medical University;

http://orcid.org/0000-0003-4983-5300

Aleksey V. Borsukov, Dr. Med. Sc., Professor, Director of Problem Research Laboratory "Diagnostic Studies and Minimally Invasive Technologies", Smolensk State Medical University;

http://orcid.org/0000-0003-4047-7252

\begin{abstract}
Objective: to define the role of transcranial electrical stimulation in the assessment of the microvascular bed by contrast-free magnetic resonance (MR) perfusion imaging in patients with chronic cerebral ischemia. Material and methods. Examinations were made in 37 people aged 65-70 years who were diagnosed with chronic cerebral ischemia. The patients were divided into two groups: with and without cognitive impairment $(\mathrm{Cl})$. The investigation algorithm involved brain magnetic resonance imaging (MRI) (Toshiba Vantage Titan, 1.5 T), transcranial electrical stimulation (TES) using a TETOS computer hardware diagnostics (Research and Production Firm "BIOSS") and repeated brain MRI in the arterial spin labelling (ASL) perfusion mode. ASL perfusion data were used to assess cerebral blood flow in the regions of interest before and after TES. Results. Contrast-free MR perfusion imaging revealed relative hyperperfusion within the cortex of the frontal and parietal lobes concurrent with hypoperfusion of the subcortical nuclei and cerebral white matter in patients with $\mathrm{Cl}$, which suggests that enhanced cortical blood flow is ineffective and shunting blood flow forms. TES caused a statistically significant change in cerebral perfusion in the non-Cl group of patients with chronic cerebral ischemia. After TES by ASL perfusion imaging, the patients without $\mathrm{Cl}$ showed a diffuse increase in cerebral blood flow $(p=0.002)$, whereas the group of apparently healthy volunteers exhibited this increase in blood flow.

Conclusion. Cerebral perfusion indices before and after TES in patients of all the examined groups define its role as a complementary tool to assess the compensatory capabilities of the microvascular bed by contrastfree MR perfusion imaging in chronic cerebral ischemia.

Keywords: transcranial electrical stimulation; chronic cerebral ischemia; ASL perfusion; magnetic resonance imaging; cerebral blood flow.

Conflict of interest. The authors declare no conflict of interest.

\section{Author contributions}

Ekaterina S. Chukhontseva - study conduction, data collection and statistical processing, data analysis and interpretation, writing the text;

Tatiana G. Morozova - study concept and design, data analysis and interpretation, text preparation and editing, responsibility for the integrity of all parts of the article;

Aleksey V. Borsukov - study concept and design, approval of the article final version
\end{abstract}


For citation: Chukhontseva ES, Morozova TG, Borsukov AV. Experience with transcranial electrical stimulation in the assessment of the microvascular bed by contrast-free magnetic resonance perfusion imaging in patients with chronic cerebral ischemia. Journal of Radiology and Nuclear Medicine. 2021; 102(6): 369-76 (in Russian). https://doi.org/10.20862/0042-4676-2021-102-6-369-376

For corresponding: Ekaterina S.Chukhontseva,E-mail: chukhontsevaes@mail.ru

\section{Введение}

Хроническая ишемия головного мозга (ХИГМ) - одно из наиболее распространенных патологических состояний в практике врача-невролога, терапевта, врача общей практики [1-3]. В настоящее время количество зарегистрированных пациентов с цереброваскулярными заболеваниями не поддается точному подсчету. Стремительный рост заболеваемости связан как с ростом продолжительности жизни, так и с увеличением доступности методов обследования среди населения [3, 4]. Несмотря на то что в мире цереброваскулярные заболевания занимают 3-е место в структуре общей смертности, составляя при этом $11,3 \%$, и уступают по частоте лишь сердечно-сосудистым заболеваниям и опухолям, часто больные не предъявляют жалоб и диагноз выставляется врачом на основании собственных наблюдений, данных осмотра и дополнительных методов обследования [4, 5].

Хроническая ишемия мозга может быть обусловлена поражением как мелких (микроангиопатия), так и крупных (стенозирующий атеросклероз) мозговых артерий, ассоциирована с сосудистыми факторами риска, такими как артериальная гипертензия, сахарный диабет, дислипидемия и др. [6-8]. При прогрессировании ХИГМ развивается неврологический дефицит, страдает психическое здоровье, происходит снижение когнитивных функций вплоть до развития деменции, что представляет одну из сложных медико-социальных и экономических проблем в большинстве развитых стран мира [9]. Согласно данным Всемирной организации здравоохранения, деменция в 2019 г. стала 7-й по распространенности причиной смерти в мире.

Стремительно растет число нейровизуализационных исследований пациентов с ХИГМ с помощью сверхвысокопольных томографов и особых методик, которые позволяют глубже изучить проблему этиологии и патогенеза данного заболевания [10]. До сих пор особняком стоит проблема ранней диагностики когнитивных нарушений при хронической ишемии мозга, а также объективной диагностики стадийности данного заболевания [11]. С 2013 г. нейрорадиологи пользуются стандартами STRIVE (STandart for Reporting Vascular changes on nEurouimaging) для описания изменений на магнитно-резонансной томограмме
(МРТ) у пациентов с ХИГМ [12]. Однако эти критерии неспецифичны для ХИГМ по отдельности и не отвечают на вопросы касательно ранних изменений вещества головного мозга, а также не определяют стадию заболевания.

Все больший интерес приобретает неинвазивная стимуляция мозга у пациентов с ХИГМ: магнитная и электрическая [13]. Данные методики применимы не только в лечебных и реабилитационных мероприятиях, но и на диагностическом поприще $[14,15]$. Транскраниальная электростимуляция (ТЭС) использует постоянный или переменный ток для стимуляции мозга. Активность нейронов в головном мозге модулируется электрическим полем в соответствии с полярностью приложенного тока $[16,17]$. При изменении нейромодуляции происходят и вазоактивные влияния на вещество головного мозга со стороны ТЭС. Данные патофизиологические изменения мало изучены в качестве диагностических паттернов ХИГМ.

В нашем исследовании принципиальный интерес вызывает использование транскраниальной электростимуляции в оценке микроциркуляторного русла методом бесконтрастной магнитно-резонансной (MP) перфузии в диагностике ХИГМ наряду с MP-критериями STRIVE.

Цель - определить роль транскраниальной электростимуляции в оценке микроциркуляторного русла методом бесконтрастной МР-перфузии у пациентов с хронической ишемией головного мозга.

\section{Материал и методы}

Настоящее исследование проходило на базе многопрофильного стационара и амбулатории ОГБУЗ «Клиническая больница № 1» г. Смоленска в 2019-2020 гг. Участие в исследовании было предложено 93 пациентам с диагнозом «хроническая ишемия головного мозга» в возрастном диапазоне от 65 до 70 лет. При получении добровольного информированного согласия от каждого больного нами был составлен список критериев исключения из исследования (эпилепсия, черепно-мозговые травмы в анамнезе, острый и ранний восстановительный период острого нарушения мозгового кровообращения (ОНМК), повреждение кожных покровов волосистой части головы, наличие стандартных противопоказаний к МРТ). 
Из 93 приглашенных 37 человек были отобраны для дальнейшего исследования: 23 (62,2\%) женщины и $14(37,8 \%)$ мужчин, средний возраст $68 \pm 1,9$ года. Пациенты находились либо на плановом стационарном лечении, либо на амбулаторном наблюдении невролога. Все больные предъявляли жалобы на незначительное снижение памяти, легкое периодическое головокружение, снижение концентрации, внимания, физическое перенапряжение, повышенную плаксивость. Диагноз ХИГМ выставлялся неврологом на основании предъявляемых жалоб, нейропсихометрического тестирования, дополняющих результатов МРТ головного мозга при исключении других нозологий.

По результатам скринингового когнитивного теста МоСа (Монреальская шкала оценки когнитивных функций) пациенты разделены на две группы: 1-я группа $(n=22)$ - больные без когнитивного дефицита (26 баллов и более), но предъявляющие жалобы на ментальные функции, 2-я группа $(n=15)$ пациенты с выраженным когнитивным дефицитом (25 баллов и менее). Контрольная группа включала 17 условно здоровых добровольцев.

Диагностический алгоритм обследования включал три этапа:

1) МРТ головного мозга при помощи магнитно-резонансного томографа Vantage Titan 1.5 (Toshiba, Япония);

2) ТЭС при помощи транскраниального компьютеризированного электростимулятора для оптимизации нейропсихологических характеристик
«ТЭТС» (ИПФ «БИОСС», Россия) (сеанс ТЭС длительностью до 7 мин проводили по центрально-сагиттальной схеме стимуляции биполярно-экспоненциальным импульсом с силой тока от 0,15 до 0,3 мА индивидуально для каждого испытуемого согласно субъективным ощущениям);

3) повторная МРТ головного мозга в режиме ASL-перфузии (arterial spin labeling - артериальная спиновая маркировка) непосредственно после стимуляции с временным размахом не более 10 мин.

Протокол МР-сканирования включал: Т1-, Т2-, Т2*-взвешенные изображения, диффузионно-взвешенные изображения, FLAIR и бесконтрастную ASL-перфузию. Все MP-паттерны оценивались двумя нейрорадиологами, которые не имели информации о жалобах пациента, его анамнезе, возрасте и различных других факторах риска ХИГМ. В случае несогласия более чем на один пункт проводили консенсусное чтение, во всех остальных случаях показания обоих врачей усреднялись. Стандартные MP-режимы применяли для визуализации критериев STRIVE и исключения патологий, не предусмотренных исследованием (ОНМК, объемные образования, травматические поражения, инфекционные заболевания мозга и его оболочек). В программе M-Power 4.0 при помощи математической функции Calculation проводили постпроцессинговую обработку изображений, полученных в режиме ASL-перфузии. Использовали программную формулу ASLscale15 (ab,0,3,4,34). С помощью

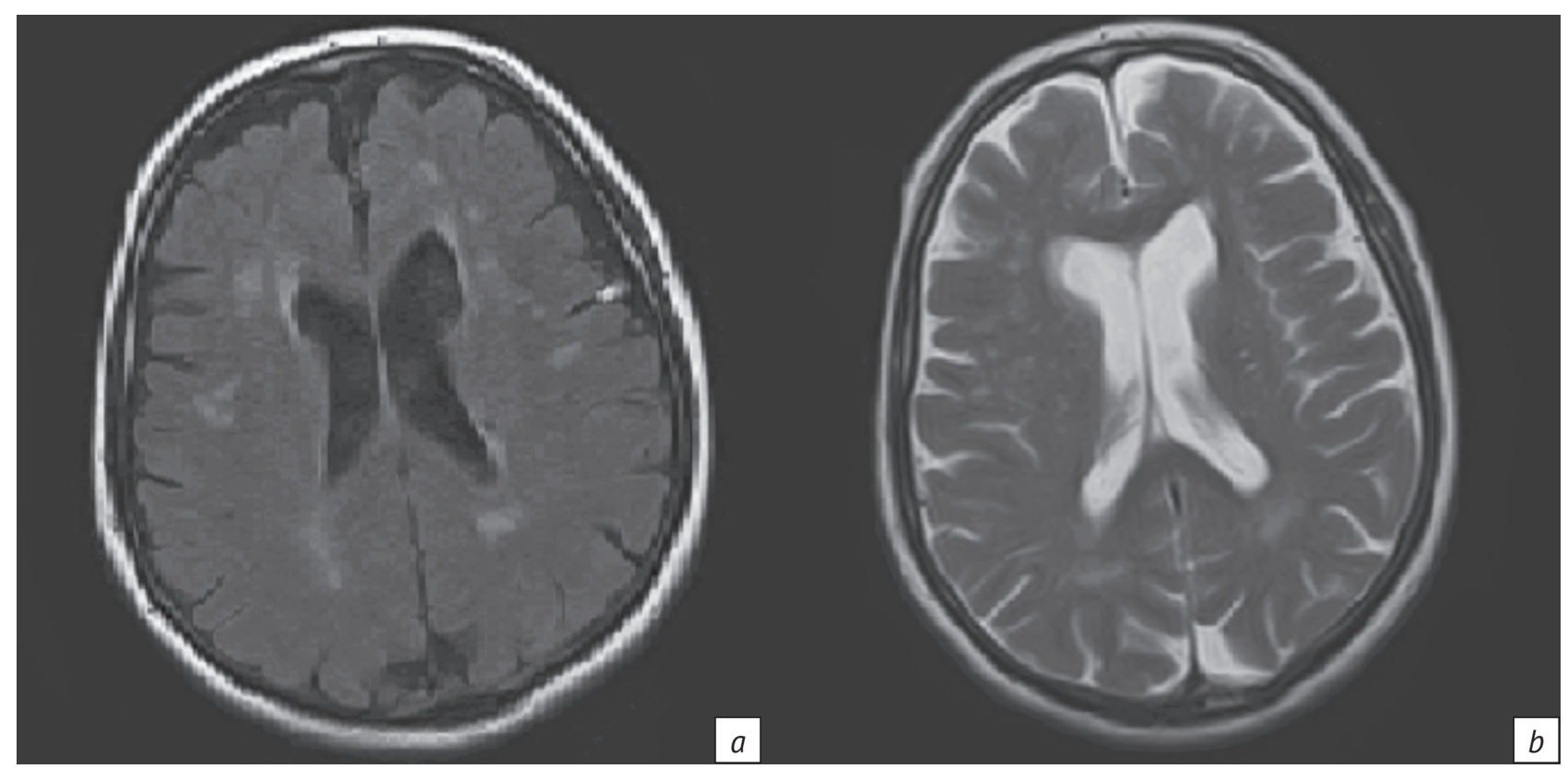

МРТ головного мозга пациентки И. 62 лет с хронической ишемией головного мозга, умеренным когнитивным снижением: $a$ - аксиальный срез FLAIR, очаги гиперинтенсивного сигнала в белом веществе головного мозга; $b$ - аксиальный срез Т2-ВИ, расширенные периваскулярные пространства

Brain MRI of a 62-year-old patient with chronic cerebral ischemia, moderate cognitive decline:

$a$ - axial FLAIR, hyperintense signal foci in the cerebral white matter; $b$ - axial T2 WI, dilated perivascular spaces 
функции Fusion сопоставляли изображения, полученные при калькулировании (3D ASL 1800 и 3D ASL 2600) и FLAIR preASL. Анализ зоны интереса (region of interest, ROI) осуществляли для расчета скорости церебрального кровотока (cerebral blood flow, CBF) в мл/100 г/мин в ROI: лобно-теменная область, подкорковые структуры, белое вещество головного мозга. Использовали усредненные значения по каждому отдельно взятому пациенту.

Полученные показатели CBF сравнивали между исследуемыми группами в ROI, а также до и после транскраниальной электростимуляции. Результаты измерений МР-паттернов и показателей церебральной перфузии заносили в базу данных в Microsoft Excel (Office 2016). Статистическую обработку данных проводили с помощью статистического пакета Statistica 6.0 с использованием методов Манна-Уитни и Краскела-Уоллиса $(p \leq 0,05)$.

\section{Результаты}

Были получены и проанализированы МР-изображения головного мозга испытуемых пациентов по критериям STRIVE - у 61 (93,8\%) больного выявлены признаки, характерные для хронической ишемии головного мозга (см. рисунок).

У $2(5,4 \%)$ пациентов признаков МР-патологии выявлено не было. Данные по частоте встречаемости того или иного признака представлены в таблице 1. У всех больных были исключены ОНМК, объемные образования, травматические поражения, инфекционные заболевания мозга и его оболочек.

Далее согласно первому этапу исследования при помощи ROI-анализа оценивали скорость церебрального кровотока в зонах интереса: лобная, теменная кора, подкорковые структуры и белое вещество головного мозга. Не выявлено статистической разницы между значениями CBF для правого и левого полушарий во всех ROI ( $p=0,0023)$. Средние значения CBF представлены в таблице 2.

Вычислены статистически значимые различия для параметра CBF во всех исследуемых областях у пациентов с ХИГМ в зависимости от наличия когнитивных расстройств (КР). Так, в лобных и теменных долях у больных 2-й группы перфузия выше, чем у пациентов 1-й группы: 91,5 [62,4; 100,3] и 71,66 [67,2; 73,6] мл/100 г/мин соответственно ( $p=0,012)$. у $13(86,67 \%)$ больных с КР определена гиперперфузия в области коры головного мозга, а также выявлено статистически значимое снижение регионарного кровотока в глубоких структурах головного мозга у всех 15 испытуемых 2-й группы $(p=0,001)$. Не зарегистрировано статистически значимых различий в показателях CBF у добровольцев контрольной группы и пациентов 1-й группы ( $p=0,1654)$.

На втором этапе исследования больным проводили ТЭС по заданной методике. Все пациенты

Таблица 1

MP-критерии хронической ишемии головного мозга по стандарту STRIVE, n (\%)

Table 1

MRI criteria of chronic cerebral ischemia according to the STRIVE standard, $n$ (\%)

\begin{tabular}{|c|c|c|c|}
\hline MP-критерии / MRI criteria & $\begin{array}{l}\text { 1-я группа, без KP / } \\
\text { Non-CI Group } 1 \\
(n=22)\end{array}$ & $\begin{array}{c}\text { 2-я группа, } \\
\text { с КР и деменцией / } \\
\text { Cl and dementia Group } 2 \\
(\mathrm{n}=15)\end{array}$ & $\begin{array}{c}\text { Контрольная группа / } \\
\text { Control group } \\
(n=17)\end{array}$ \\
\hline Лакуны / Lacunae & $2(9,09)$ & $3(20,0)$ & $0(0)$ \\
\hline $\begin{array}{l}\text { Гиперинтенсивность белого вещес } \\
\text { White matter hyperintensity } \\
\text { Fazekas } 1 \\
\text { Fazekas } 2 \\
\text { Fazekas } 3\end{array}$ & $\begin{array}{c}8(36,36) \\
0(0) \\
0(0)\end{array}$ & $\begin{array}{c}0(0) \\
5(33,33) \\
10(66,67)\end{array}$ & $\begin{array}{c}5(29,41) \\
0(0) \\
0(0)\end{array}$ \\
\hline $\begin{array}{l}\text { Перивакулярные пространства / } \\
\text { Perivascular spaces } \\
\text { I тип / Type } 1 \\
\text { II тип / Type } 2 \\
\text { III тип / Type } 3\end{array}$ & $\begin{array}{c}3(13,63) \\
0(0) \\
0(0)\end{array}$ & $\begin{array}{c}1(6,67) \\
4(26,67) \\
3(20,0)\end{array}$ & $\begin{array}{c}2(11,76) \\
0(0) \\
0(0)\end{array}$ \\
\hline $\begin{array}{l}\text { Микрокровоизлияния / } \\
\text { Microhemorrhages }\end{array}$ & $0(0)$ & $1(6,67)$ & $0(0)$ \\
\hline Атрофия / Atrophy & $0(0)$ & $3(20,0)$ & $0(0)$ \\
\hline
\end{tabular}

Примечание. КР - когнитивные расстройства.

Note. $\mathrm{Cl}$ - cognitive impairment. 
Медианы скорости церебрального кровотока в зонах интереса головного мозга до и после воздействия транскраниальной электростимуляции, мл/100 г/мин

Table 2

Median cerebral blood flow velocities in the regions of interest in brain before and after transcranial electrical stimulation, $\mathrm{mL} / 100 \mathrm{~g} / \mathrm{m}$

\begin{tabular}{|c|c|c|c|c|c|c|}
\hline \multirow[t]{2}{*}{$\begin{array}{l}\text { Зона интереса / } \\
\text { Region of interest }\end{array}$} & \multicolumn{2}{|c|}{$\begin{array}{c}\text { 1-я группа, без KP / } \\
\text { Non-Cl Group } 1 \\
(n=22)\end{array}$} & \multicolumn{2}{|c|}{$\begin{array}{c}\text { 2-я группа, с КР } \\
\text { и деменцией / } \\
\mathrm{Cl} \text { and dementia Group } 2 \\
(\mathrm{n}=15)\end{array}$} & \multicolumn{2}{|c|}{$\begin{array}{c}\text { Контрольная группа / } \\
(\mathrm{n}=17)\end{array}$} \\
\hline & До / Before & После / After & До / Before & После / After & До / Before & После / After \\
\hline $\begin{array}{l}\text { Лобная и теменная кора / } \\
\text { Frontal and parietal cortex }\end{array}$ & $\begin{array}{c}71,6 \\
{[62,2 ; 73,6]}\end{array}$ & $\begin{array}{c}76,8 \\
{[70,5 ; 78,3]}\end{array}$ & $\begin{array}{c}91,5 \\
{[58,4 ; 100,3]}\end{array}$ & $\begin{array}{c}92,5 \\
{[60,1 ; 101,4]}\end{array}$ & $\begin{array}{c}70,6 \\
{[66,2 ; 74,6]}\end{array}$ & $\begin{array}{c}71,3 \\
{[68,1 ; 73,9]}\end{array}$ \\
\hline $\begin{array}{l}\text { Подкорковые ядра / } \\
\text { Subcortical nuclei }\end{array}$ & $\begin{array}{c}57,6 \\
{[51,2 ; 60,3]}\end{array}$ & $\begin{array}{c}58,5 \\
{[51,9 ; 62,6]}\end{array}$ & $\begin{array}{c}31,3 \\
{[30,2 ; 33,5]}\end{array}$ & $\begin{array}{c}31,8 \\
{[29,8 ; 34,5]}\end{array}$ & $\begin{array}{c}55,7 \\
{[49,4 ; 60,9]}\end{array}$ & $\begin{array}{c}56,0 \\
{[49,3 ; 61,5]}\end{array}$ \\
\hline $\begin{array}{l}\text { Белое вещество / } \\
\text { White matter }\end{array}$ & $\begin{array}{c}48,0 \\
{[45,4 ; 53,5]}\end{array}$ & $\begin{array}{c}50,2 \\
{[46,8 ; 55,6]}\end{array}$ & $\begin{array}{c}29,0 \\
{[23,1 ; 31,2]}\end{array}$ & $\begin{array}{c}30,8 \\
{[24,8 ; 31,5]}\end{array}$ & $\begin{array}{c}49,0 \\
{[44,8 ; 54,0]}\end{array}$ & $\begin{array}{c}50,1 \\
{[44,6 ; 55,9]}\end{array}$ \\
\hline
\end{tabular}

удовлетворительно чувствовали себя во время и после сеанса ТЭС

На третьем этапе по данным ASL-перфузии при сопоставлении исследуемых групп до и после транскраниальной стимуляции вычисляли статистически значимые различия для скорости церебральной перфузии в 1-й группе (см. табл. 2). Показатель выше в 90,9\% ( $n=20$ ) случаев как в лобной и теменной коре головного мозга, так и в белом веществе и подкорковых ядрах: средний прирост CBF в обоих полушариях составил 5,6\% (4 1,45 мл/100 г/ мин, $\mathrm{p}=0,002)$. Статистически значимых изменений церебральной перфузии не выявлено в контрольной группе: прирост составил не более $1 \%$ (0,7 \pm 0,43 мл/100 г/мин, p = 0,0913). В контрольной группе церебральный кроток после ТЭС изменился на 1,1\% (1,0 \pm 0,32 мл/100 г/мин, $p=0,075)$.

\section{Обсуждение}

Первичный механизм изменения церебральной перфузии у пациентов с ХИГМ состоит в изменении сосудистой стенки с ее повышенной проницаемостью и, как следствие, перивентрикулярным отеком, вторичным сдавлением венул и нарушением венозного оттока [18]. В таких условиях уменьшается содержание кислорода и глюкозы, происходит сдвиг метаболизма в сторону анаэробного гликолиза, гиперосмолярности и лактатацидоза. Мозговая ткань все больше пытается восполнить дефицит поглощением кислорода из артериальной крови, в результате чего изменяются форменные элементы крови, возникает склонность к микротромбозам. Нарастающие лактатацидоз и гиперосмолярность приводят к ухудшению перфузии, вплоть до развития стаза, что особенно ха- рактерно для глубоких структур вещества головного мозга у пациентов с КР.

Вторичным механизмом является нарушение ауторегуляции микрососудистого русла с проявлением все большей зависимости от системной гемодинамики. С увеличением возраста происходит снижение фракции выброса сердечной мышцы как явление нормального старения организма. В ранних исследованиях показана большая распространенность КР среди пациентов с сердечной недостаточностью. Вдобавок зависимость гипоперфузии от системной гемодинамики приводит к артериальной гипотензии на фоне приема препаратов, снижающих давление [19].

Третьим аспектом является нарушение нейрогенной регуляции системной и церебральной гемодинамики. У пациентов с когнитивными расстройствами сочетание обедненного кровотока со значительной гиперперфузией коры головного мозга может свидетельствовать о нарушении нейроваскулярного взаимодействия [20]. Исходя из уровня когнитивного дефицита мы говорим о неэффективности усиления кровотока при формировании артериовенулярных шунтов с невозможностью достаточного извлечения глюкозы на уровне капилляров. L. Østergaard et al. описывают этот феномен как капиллярную дисфункцию и определяют одну из ведущих ролей в формировании КР у пациентов с ХИГМ [7].

Р.Н. Коновалов также определяет патогенетический механизм выраженности когнитивного дефицита у пациентов с субкортикальной атеросклеротической энцефалопатией (одной из форм ХИГМ) в результате диффузного поражения белого вещества мозга. Это приводит к разобщению коры 
головного мозга, подкорковых структур и лимбикоретикулярного комплекса, что влечет за собой функциональную инактивацию коры.

Рассматривая данные, полученные на третьем этапе исследования, важно отметить, что анодная стимуляция постоянным током по центрально-сагиттальной схеме расположения электродов вызывает повышение церебральной перфузии у пациентов с визуально нормальным кровотоком без когнитивного дефицита по сравнению с испытуемыми контрольной группы и больными с КР. Мы объясняем это тем, что под воздействием ТЭС клетки мозга поляризуются и повышается их резервная нейрональная активность, что приводит к усилению регионарного кровотока. У пациентов с деменцией компенсаторные возможности нейро- и вазоактивности как в коре головного мозга, так и в подкорковых ядрах низки, что определяет неэффективность ТЭС.

\section{Заключение}

В работе описан положительный опыт применения транскраниальной электростимуляции при оценке микроциркуляторного русла методом бесконтрастной МР-перфузии у пациентов с ХИГМ. После воздействия ТЭС у больных без когнитивных расстройств методом ASL-перфузии выявлено диффузное усиление церебрального кровотока при относительно нормальных исходных показателях ( $p=0,002)$, тогда как в группе условно здоровых добровольцев подобного нарастания кровотока не отмечено.

Показатели церебральной перфузии до и после ТЭС у пациентов всех исследуемых групп определяют роль ТЭС как дополняющего звена в оценке компенсаторных возможностей микрососудистого русла методом бесконтрастной МР-перфузии у больных ХИГМ.

\section{Литература}

1. Раимкулов Б.Н. Цереброваскулярные расстройства (обзор литературы). Вестник Казахского Национального медицинского университета. 2014; 2(1): 185-8.

2. Шавловская О.А. В здравом уме и твердой памяти. Non Nocere. Новый терапевтический журнал. 2018; 11: 39-43.

3. Гудкова В.В., Стаховская Л.В. Хроническая недостаточность мозгового кровообращения. Справочник поликлинического врача. 2004; 5: 47-51.

4. Яхно Н.Н., Левин О.С., Дамулин И.В. Сопоставление клинических и МРТ-данных при дисциркуляторной энцефалопатии. Сообщение 2: когнитивные нарушения. Неврологический журнал. 2001; 6(3): 10-9.

5. Живолупов С.А., Самарцев И.Н. Современный клинический анализ цереброваскулярных заболеваний: узловые вопросы дифференциальной диагностики и патогенетического лечения. Фарматека. 2012; 7: 93-100.

6. Сергеева А.Н., Добрынина Л.А., Гаджиева 3.Ш. и др. Церебральный кровоток, измеренный с помощью MPТ в режиме маркировки артериальных спинов (arterial spin labeling ASL), и МРТ-признаки возраст-зависимой церебральной микроангиопатии (болезни малых сосудов). Российский электронный журнал лучевой диагностики. 2019; 9(4): 8-17. https://doi.org/10.21569/2222-7415-2019-9-4-8-17.

7. Østergaard L, Thorbjørn SE, Moreton F, et al. Cerebral small vessel disease: capillary pathways to stroke and cognitive decline.J Cereb Blood Flow Metab. 2016; 36(2): 302-25. https://doi.org/10.1177/0271678×15606723.

8. Захаров В.В., Громова Д.О. Диагностика и лечение хронической недостаточности мозгового кровообращения. Эффективная фармакотерапия. 2015; 13: 48-54.

9. Шмонин А.А., Краснов В.С., Шмонина И.А., Мельникова Е.В. Современная терапия хронического нарушения мозгового кровообращения. Неврология, нейропсихиатрия, психосоматика. 2015; 7(1): 99-106. https://doi.org/10.14412/2074-2711-2015-1-99-106.

10. Кремнева Е.И., Суслин А.С., Добрынина Л.А., Кротенкова М.В. Как распознать возраст-зависимую церебральную микроангиопатию (болезнь мелких сосудов) на МРТ: алгоритм исследования. Российский электронный журнал лучевой диагностики. 2020; 10(4): 186-206.

https://doi.org/10.21569/2222-7415-2020-10-4-186-206.

11. Чухонцева Е.С., Морозова Т.Г., Борсуков А.В. Нейровизуализационные паттерны хронической недостаточности мозгового кровообращения с оценкой церебральной перфузии в зависимости от уровня когнитивных расстройств. Медицинская визуализация. 2020; 24(3): 114-22. https://doi.org/10.24835/1607-0763-2020-3-114-122.

12. Wardlaw JM, Smith EE, Biessels GJ, et al. Neuroimaging standards for research into small vessel disease and its contribution to ageing and neurodegeneration. Lancet Neurol. 2013; 12(8): 822-38. https://doi.org/10.1016/s1474-4422(13)70124-8.

13. Rothwell J. Transcranial brain stimulation: past and future. Brain Neurosci Adv. 2018; 2: 1-4. https://doi.org/10.1177/2398212818818070.

14. Звоников В.М., Грищенко А.В., Герасин И.К. Применение электростимулятора транскраниального компьютеризированного с обратной связью для оптимизации нейропсихологических характеристик «ТЭТОС» (методические рекомендации). М.: ОАО «Российские железные дороги»; 2006.

15. Электростимулятор транскраниальный компьютеризированный с обратной связью для оптимизации нейропсихилогических характеристик «ТЭТОС»: руководство по эксплуатации. М.: НПФ «БИОСС»; 2006.

16. Dissanayaka T, Zoghi M, Farrell M, et al. Does transcranial electrical stimulation enhance corticospinal excitability of the motor cortex in healthy individuals? A systematic review and meta-analysis. Eur J Neurosci. 2017; 46(4): 1968-90. https://doi.org/10.1111/ejn.13640.

17. Solomons CD, Shanmugasundaram V. A review of transcranial electrical stimulation methods in stroke rehabilitation. Neurol India. 2019; 67(2): 417-23. https://doi.org/10.4103/0028-3886.258057.

18. Гурьева П.В., Быков Ю.Н., Васильев Ю.Н. (сост.) Дисциркуляторная энцефалопатия: учебное пособие для врачей. Иркутск: ИГМУ; 2017. 
19. Дамулин И.В. Дисциркуляторная энцефолопатия: патогенетические, клинические и терапевтические аспекты. Трудный пациент. 2005; 3(6): 11-7.
20. Dai W, Lopez OL, Carmichael OT, et al. Mild cognitive impairment and Alzheimer disease: patterns of altered cerebral blood flow at MR imaging. Radiology. 2009; 250(3): 856-66. https://doi.org/10.1148/radiol.2503080751.

\section{References}

1. Raimkulov BN. Cerebrovascular disorders (literature review). Vestnik KazNMU. 2014; 2(1): 185-8 (in Russ.).

2. Shavlovskaya OA. Being of sound mind and body. Non Nocere. New Therapeutic Journal. 2018; 11: 39-43 (in Russ.)

3. Gudkova VV, Stakhovskaya LV. Chronic insufficiency of cerebral circulation. Spravochnik poloclinicheskogo vracha / Guide for polyclinic doctor. 2004; 5: 47-51 (in Russ.).

4. Yakhno NN, Levin OS, Damulin IV. Comparison of clinical and MRI data in dyscirculatory encephalopathy. Report 2: Cognitive impairment. The Neurological Journal. 2001; 6(3): 10-9 (in Russ.).

5. Zhivolupov S.A., Samartsev I.N. Modern clinical analysis of cerebrovascular diseases: key issues of differential diagnosis and pathogenetic treatment. Farmateka. 2012; 7: 93-100 (in Russ.)

6. Sergeeva AN, Dobryinina LA, Gadgieva ZSh, et al. Cerebral blood flow measured with mri arterial spin labeling (asl) and neuroimaging signs of age-related small vessel disease. Russian Electronic Journal of Radiology. 2019; 9(4): 8-17 (in Russ.). https://doi.org/10.21569/2222-7415-2019-9-4-8-17.

7. Østergaard L, Thorbjørn SE, Moreton F, et al. Cerebral small vessel disease: capillary pathways to stroke and cognitive decline.J Cereb Blood Flow Metab. 2016; 36(2): 302-25. https://doi.org/10.1177/0271678x15606723.

8. Zakharov V, Gromova DO. Diagnostics and treatment of chronic cerebrovascular insufficiency. Effektivnaya farmakoterapiya / Effective Pharmacotherapy. 2015; 13: 48-54 (in Russ.).

9. Shmonin A.A., Krasnov V.S., Shmonina I.A., Melnikova E.V. Current therapy for chronic cerebrovascular attack. Neurology, Neuropsychiatry, Psychosomatics. 2015; 7(1): 99-106 (in Russ.). https://doi.org/10.14412/2074-2711-2015-1-99-106.

10. Kremneva EI, Suslin AS, Dobrynina LA, Krotenkova MV. MRI in the diagnosis of age-related small vessel disease: instruction for radiologist. Russian Electronic Journal of Radiology. 2020; 10(4): 186-206 (in Russ.). https://doi.org/10.21569/2222-7415-2020-10-4-186-206.
11. Chukhontseva ES, Morozova TG, Borsukov AV. Neuroimaging patterns of chronic cerebrovascular insufficiency with evaluation of cerebral perfusion depending on the level of cognitive disorders. Medical Visualization. 2020; 24(3): 114-22 (in Russ.) https://doi.org/10.24835/1607-0763-2020-3-114-122.

12. Wardlaw JM, Smith EE, Biessels GJ, et al. Neuroimaging standards for research into small vessel disease and its contribution to ageing and neurodegeneration. Lancet Neurol. 2013; 12(8): 822-38. https://doi.org/10.1016/s1474-4422(13)70124-8.

13. Rothwell J. Transcranial brain stimulation: past and future. Brain Neurosci Adv. 2018; 2: 1-4. https://doi.org/10.1177/2398212818818070.

14. Zvonikov VM, Grishchenko AV, Gerasin IK. Application of TETOS transcranial computerized electrical stimulator with feedback to optimize neuropsychological characteristics (methodological recommendations). Moscow: 2006 (in Russ.).

15. TETOS transcranial computerized electrical stimulator with feedback to optimize neuropsychological characteristics: user manual. Moscow; 2006 (in Russ.).

16. Dissanayaka T, Zoghi M, Farrell M, et al. Does transcranial electrical stimulation enhance corticospinal excitability of the motor cortex in healthy individuals? A systematic review and meta-analysis. Eur J Neurosci. 2017; 46(4): 1968-90. https://doi.org/10.1111/ejn.13640.

17. Solomons CD, Shanmugasundaram V. A review of transcranial electrical stimulation methods in stroke rehabilitation. Neurol India. 2019; 67(2): 417-23. https://doi.org/10.4103/0028-3886.258057.

18. Guryeva PV, Bykov YuN, Vasiliev YuN (comp.) Dyscirculatory encephalopathy: a textbook for doctors. Irkutsk: IGMU; 2017 (in Russ.).

19. Damulin IV. Dyscirculatory encephalopathy: pathogenetic, clinical and therapeutic aspects. Difficult Patient. 2005; 3(6): 11-7 (in Russ.)

20. Dai W, Lopez OL, Carmichael OT, et al. Mild cognitive impairment and Alzheimer disease: patterns of altered cerebral blood flow at MR imaging. Radiology. 2009; 250(3): 856-66. https://doi.org/10.1148/radiol.2503080751. 